Supplement of Nat. Hazards Earth Syst. Sci., 21, 1807-1823, 2021

https://doi.org/10.5194/nhess-21-1807-2021-supplement

(C) Author(s) 2021. CC BY 4.0 License.

(c) (i)

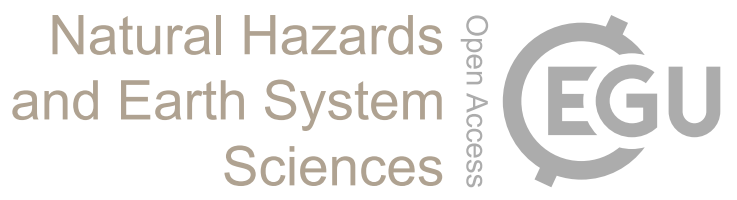

Supplement of

\title{
Predicting social and health vulnerability to floods in Bangladesh
}

Donghoon Lee et al.

Correspondence to: Donghoon Lee (dlee@geog.ucsb.edu)

The copyright of individual parts of the supplement might differ from the article licence. 


\section{Supplement}

\section{Introduction}

This Supplement includes 4 figures (Figures S1-S4).

- Figure S1 illustrates the gridded population in Bangladesh.

- Figure S2 illustrates the vulnerability scores of the selected principal components in each domain.

- Figure S3 illustrates the percentage of affected population in Upazila-scale.

- Figure S4 illustrates the district-level social-health vulnerabilities.

The processed and completed indicators and vulnerabilities are available on Zenodo: http://doi.org/10.5281/zenodo.4718085. 


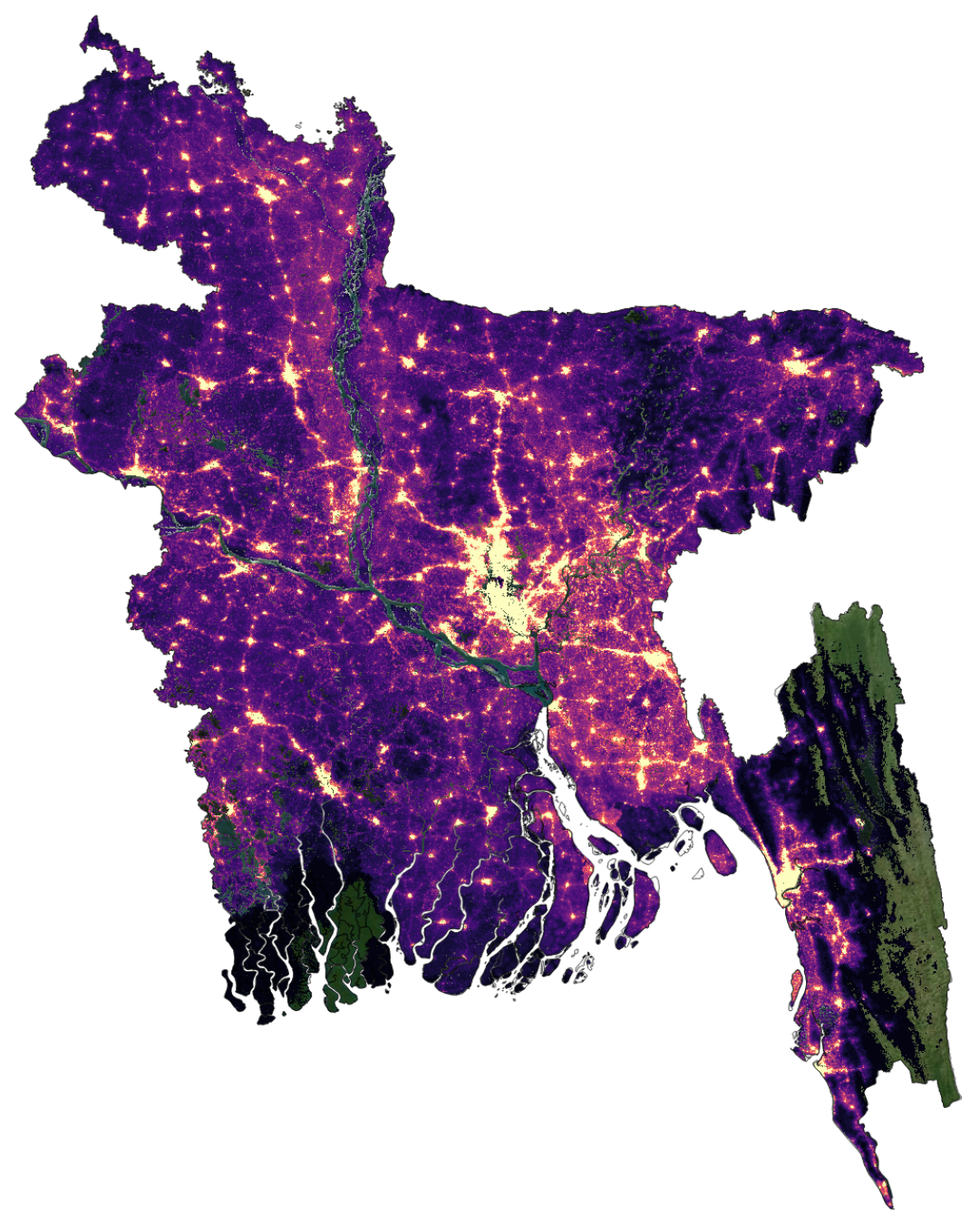

Figure S1. Worldpop's population per pixel data in Bangladesh (Worldpop et al., 2018). 


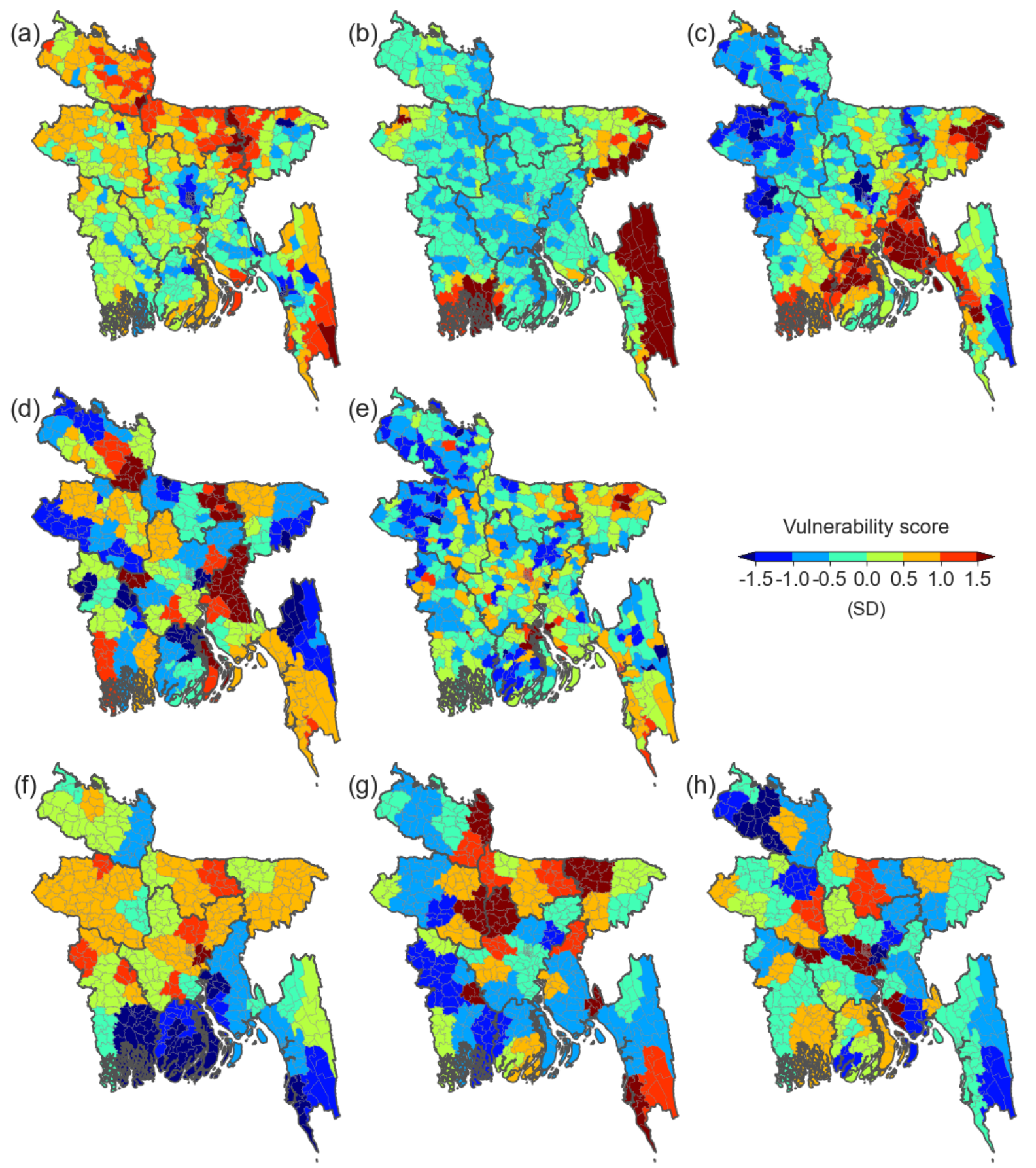

Figure S2. The vulnerability scores of the selected principal components in (a-c) socio-economic, (d and e) health, and (f-h) coping capacity domains. 


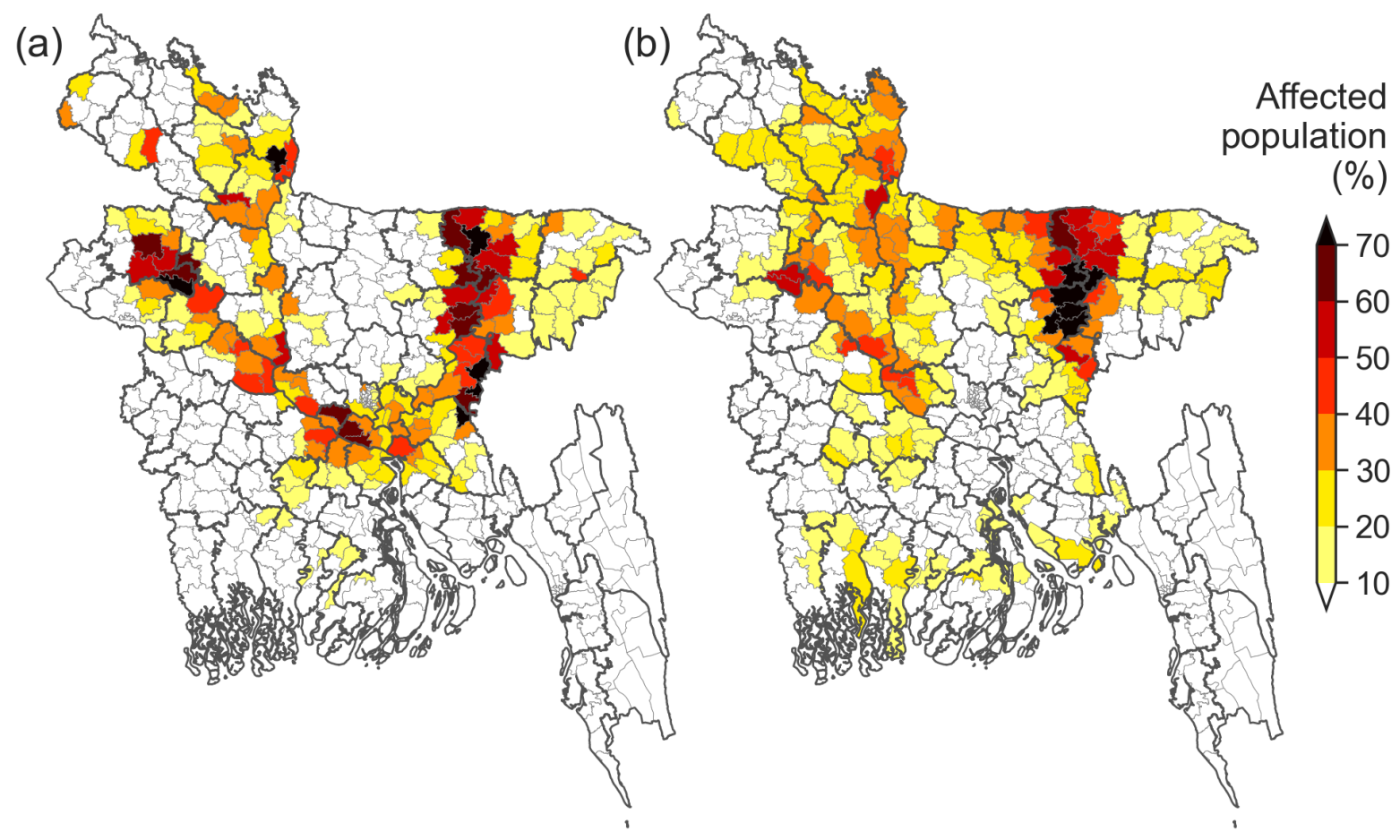

Figure S3. Percentage of affected population by the August 2017 flood event estimated from (a) flood forecast and (b) satellite inundation 


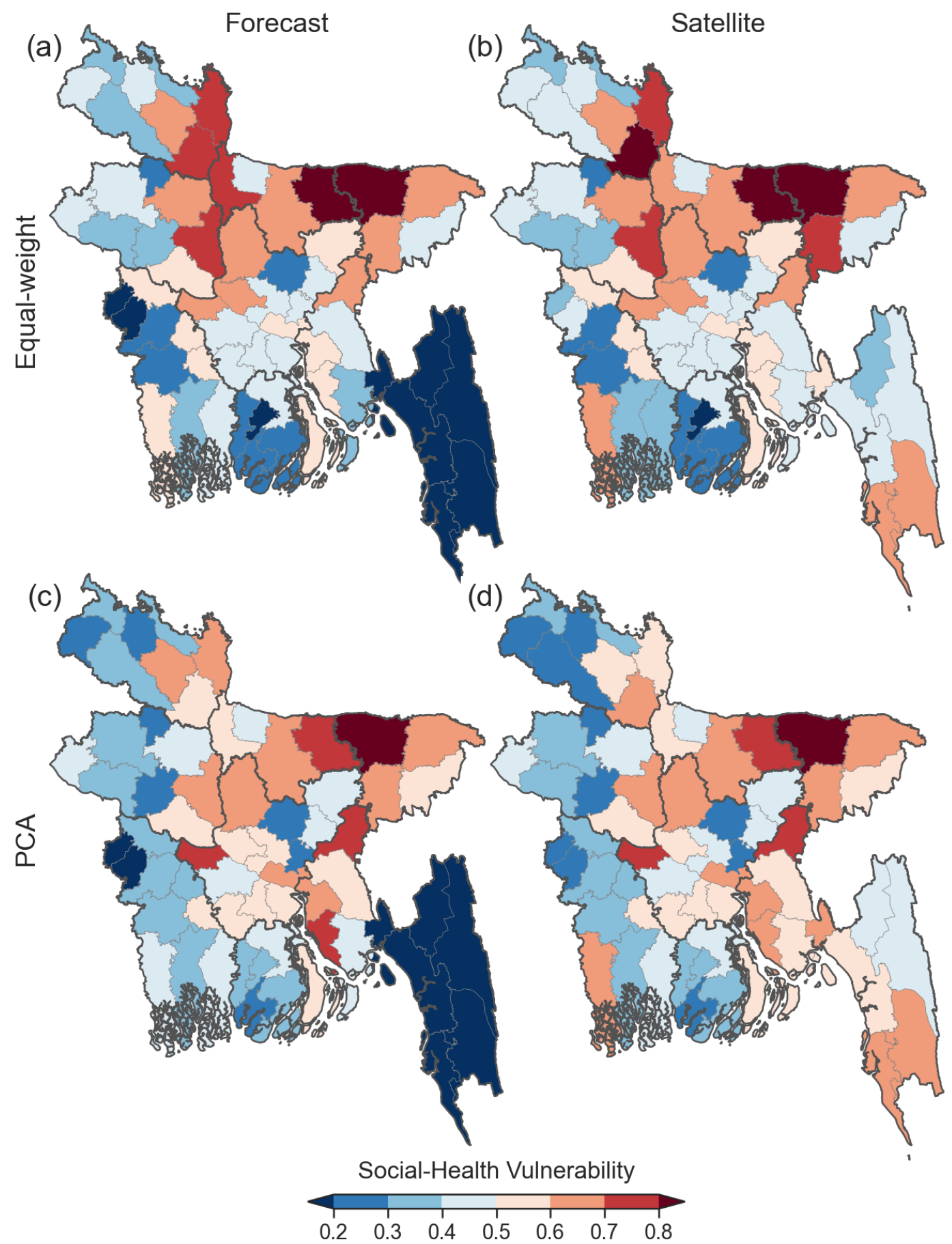

Figure S4. District-level social-health vulnerability (SHV). The top and bottom panels represent the FHV determined by the equal weight and PCA approaches, respectively, while the left and right panels represent the flood forecast and satellite inundation-driven SHV, respectively 


\section{References}

Worldpop, Department of Geography and Geosciences University of Louisville, Department de Geographie Universite de Namur, and

10 CIESIN Columbia University: Global High Resolution Population Denominators Project, https://doi.org/10.5258/SOTON/WP00645, http://www.worldpop.org.uk/, 2018. 